\title{
An integrated MCDM approach to evaluate public transportation systems in Tehran
}

\author{
M. Nassereddine ${ }^{1^{*}} ;$ H. Eskandari ${ }^{2}$
}

\author{
${ }^{1}$ Ph.D. Student, Department of Industrial Management, Tarbiat Modares University, Tehran, Iran \\ ${ }^{2}$ Assistant Professor, Department of Industrial Engineering, Tarbiat Modares University, Tehran, Iran
}

\begin{abstract}
Public transportation is one of the most important systems in transportation, especially in big and crowded cities. As a result, evaluation of public transportation systems is a strategic decision-making problem for both private and public sections. In this paper, the problem of public transportation passengers in Tehran is addressed and their satisfaction levels are assessed by using passenger satisfaction survey. An integrated MCDM approach is proposed for evaluation of public transportation systems based on Delphi method, group analytic hierarchy process (GAHP) and preference ranking organization method for enrichment of evaluations (PROMETHEE). The proposed model provides more reliable and realistic results and introduces directions for future improvements of public transportation service quality. A sensitivity analysis is applied to investigate the influence of criteria weights on the decision making problem. As a conclusion, the most important public transportation systems in Tehran orderly are: metro, taxi, BRT, bus and van. Therefore, Tehran Municipality and policy makers should encourage and support the previously mentioned systems.
\end{abstract}

Keywords: MCDM; Public transportation system; Delphi method; GAHP; PROMETHEE

\section{Introduction}

During the past twenty years, developing countries have experienced very huge population growth (Buhaug \& Urdal, 2013). The increase in population in Iran has led to the increase in the demand for urban transport in megacities, especially in the capital city of Tehran. Although the importance of public transportation is increasing with rapid growing population of Tehran, the transport infrastructure is not appropriate for the current transport demand. This has caused serious traffic congestion on the streets of the city that overloads the public transport in rush hours; this increases the queue length and waiting time for passengers. Under these conditions, a large part of people are compelled to use their private cars in contrast to their preference to use the public transportation, which plays a crucial role in facilitating the mobility of citizens (Lodovici \& Torchio, 2015). By using more private cars, the transportation system's situation becomes worse because these cars are the main reason for congestion on the roads and the increase of environmental pollution.

Understanding the behavioral intentions of public transit passengers is critical (Lai \& Chen, 2011), and ensuring a high customer satisfaction level in public transportation system is a fundamental mission for the managers and authorities (Aydin et al., 2015). Therefore, Municipality of Tehran and some transport companies have become more knowledgeable of the important role played by customer satisfaction in order to increase the utilization of public transport and decrease the private transport. As a result, improvements can attract more users to use public transportation.

In this paper, the problem of public transportation customers in Tehran is discussed and the customer satisfaction survey is used to evaluate their satisfaction levels. For this purpose, Delphi-GAHP-PROMETHEE integrated approach for ranking public transportation modes in Tehran is introduced, and the implementation process is explained with a real world case.

The aim of using the Delphi method is to know the most important criteria via experts' opinions and questionnaires. It can be applied to iteratively process opinions of experts until a general agreement is reached on the subject under investigation (Emovon et al., 2015), and also to forecast and identify critical issues (Ramos et al., 2016).

The group AHP method is used to analyze the structure of the public transportation passengers' problem with the help of a panel of experts and determine the weight of the criteria. Group decision making has become a crucial and intensely important part of multiple criteria decision making (Ahmad et al., 2014; Wang et al., 2014; $;$ u and Lai, 2011), and a group can better overcome the complexity of the problem than a single decision

*- Corresponding author. E-mail: m.nassereddine@ modares.ac.ir

Tel.: + 989334686899 
maker (DM) (Grošelj et al., 2015). The advantages of AHP over other multi-criteria methods, as often cited by its proponents, are its flexibility, intuitive appeal to the decision-makers (experts), and finally its potency to test the inconsistencies in judgments (Saaty, 2000).

Finally, PROMETHEE method is employed for final ranking of public transportation modes. This is followed by a geometrical analysis for an interactive aid (GAIA) plane to identify conflicts among the criteria and to group the alternatives, as well as the sensitivity analysis of different scenarios by changing the criteria weights. The simultaneous consideration of quantitative and qualitative criteria is the advantage of PROMETHEE method. Moreover, PROMETHEE permits the decision-maker to take unclear, incomplete, incomparable or even contradictory information and thus preferences into consideration since it has the possibility to define threshold values, strict preference indefinite preferences and indifferences (Meier, 2013). Another benefit of applying PROMETHEE over other non-compensatory methods, is simplifying the preference modeling, since as often cited by its proponents the decision makers find it easy to understand the concepts and parameters inherent in the method. (Silva \& Schramm, 2015). The PROMETHEE method with its tools (GAIA plane, walking weights, stability intervals, multiple comparisons and preference flows) enables the decisionmakers to better control the process using real data of the alternatives.

In spite of the existence of some integrated MCDM models that used Delphi, AHP and PROMETHEE simultaneously (Mousavi et al., 2013), but to the best of our knowledge, there is no study to evaluate public transport modes integrating Delphi, GAHP and PROMETHEE techniques. Hence, the integrated novel MCDM proposed in the present study benefits from the advantages of all methods by combining Delphi, GAHP and PROMETHEE. So, the results of the evaluation of public transportation system by MCDM methods can be used by Tehran Municipality for more realistic decision-making situation and more reliable investment appraisal.

The remainder of this paper is organized in the following manner. In Section 2, the literature review on customer satisfaction and MCDM methods in public transportation systems are presented. In Section 3, a brief introduction of Delphi, GAHP and PROMETHE along with the proposed methodology are given. The applicability of the proposed method on public transportation systems in Tehran is described in Section 4. The GAIA and sensitivity analysis of the results are given in Section 5. Conclusions and directions for future research are dealt with in Section 6.

\section{Literature review}

This section aims to review the customer satisfaction as well as the application of MCDM in public transportation.

\subsection{Customer satisfaction in public transportation}

Evaluation of the transportation service quality is the first step of increasing customer satisfaction in any system (Awasthi et al., 2011). There are many studies that focus on customer satisfaction in public transportation, understanding how to positively it influences public transit users' behavioral intentions for the future, and thereby influences users' loyalty (van Lierop and El-Geneidy, 2016; Stelzer et al., 2016; Mouwen, 2015; Lai and Chen, 2011).

Celik et al. (2014) proposed a framework which assesses the five rail transit lines in Istanbul(Turkey) for 2012. The study of Tyrinopoulos and Antoniou (2008) aimed to evaluate and understand better passenger attitudes toward public transport modes. This study explains the loyalty model and demonstrates its use in transportation using a case study of a choice between two modes, rail and bus. Friman and Fellesson (2009) analyzed the relationship between the objective performance measures of public transport services and the passenger satisfaction. Lai and Chen (2011) evaluated the relationships between the behavioral intentions of public transit passengers and the various factors that influence them. The paper aims to address the importance of the involvement of public transit services in passengers, behavioral intentions. Fellesson and Friman (2012) compared the perceived service satisfaction with public transport in eight European countries. This paper recognizes the four satisfaction dimensions of system, comfort, staff, and safety, which were present in most, but not all, of the cities. These findings demonstrate that there are disagreements in how public transport is 
perceived. Also Nathanai. (2011) present a framework expanded for helping railway operators into monitoring and controlling the quality of services provided to the railway passengers.

Del Castillo and Benitez (2012) offered a methodology to identify the aspects that mostly affect the perception of the overall quality of service. The paper aimed to define and quantify the relationship between the ratings given to the overall satisfaction and those given to the specific aspects of the service or specific ratings. Hassan et al. (2013) suggested a multi-level framework in order to measure public transit service performance. The paper allows for the opinions of the various stakeholders of public transit services to join a multi-criteria evaluation process. Mouwen and Rietveld (2013) analyzed the public transportation in the Netherlands to search whether competitiveness raises the customer satisfaction in public transportation. They suggested that new vehicles highly influence the customer satisfaction. An evaluation for the efficiency of public transport operations undertaken in Swedish counties by the public transport authorities was proposed by Holmgren (2013) ,this evaluation considers the substantial differences in operating conditions between the counties.

Recently, Mouwen (2015) presented a methodology aiming at improving the understanding of the drivers of customer satisfaction with public transport. The paper provides a related contribution to the past studies since through the highlighting the complex interaction between the level and composition of satisfaction, negative social safety experiences, urban settings, and the public transport mode utilized. Eboli and Mazzulla (2015) proposed a methodology for measuring transit service quality. This methodology is based on the use of both passenger perceptions and transit agency performance measures focusing on the fundamental status characterizing a transit service. van Lierop and El-Geneidy (2016) examined how the transit users' perceptions of service quality and user satisfaction influence loyalty. The study further attempts to clarify the complexities of various factors affecting passenger satisfaction and behavioral intentions. In order to improve the service quality of public transport Stelzer et al. (2016) evaluate the necessity for standardized automated information exchange between travelers and transportation companies. In this study, interests for customers and transportation companies in regard to service quality are also mentioned.

\subsection{MCDM in public transportation}

MCDM methodologies are rapidly growing in the public transportation problems. Pérez et al. (2015) assert that 58 different MCDM techniques have been applied in urban passenger transport systems between 1982 and 2014 concluding that MCDM techniques has become one of the potent beneficial techniques for the evaluation and decision making projects in public transportation systems in the last decades. Therefore, MCDM has turned into one of the essential decision making techniques utilized by some researchers, academicians and authorities in the customer satisfaction evaluation of public transportation systems (Pérez et al., 2015; Celik et al., 2013; Awasthi et al., 2011).

Chou et al. (2011) applied MCDM to evaluate the performance of Taiwanese airlines hence suggesting improvements to increase service quality. Also Tzeng et al. (2005) compared and applied two MCDM methods to set the extreme appropriate alternative fuel mode. The results showed that the hybrid electric bus is the extreme appropriate substitute bus for Taiwan urban areas in the short and median terms.

Yedla and Shrestha (2003) used AHP to evaluate six sustainable transportation modes. Tsamboulas and Mikroudis (2000) presented a multi-criteria evaluation agenda of environmental effects and costs of transport initiatives. Awasthi and Omrani (2009) show an AHP and belief theory based method in order to calculate sustainable transportation solutions.

PROMETHEE is a MCDM method that was originally proposed by Brans and extended by Brans and Vincke Brans and Vincke (1985). It has been functional in solving a diversity of MCDM problems. PROMETHEE is a relatively simple ranking method in conception and application compared with other MCA methods (Behzadian et al., 2010). Dulmin and Mininno (2003) in order to select the related suppliers they used PROMETHEE for an outsourcing research, by performing for a mid-sized Italian firm operating in the domain of public road and rail transportation. Elevli and Demirci (2004) employed PROMETHEE I and II to select the most adequate underground ore transport system for a chromite's mine in Turkey. The integrated AHP and PROMETHEE applied in other field due to its advantages. Kabir and Sumi (2014a) by using fuzzy analytic hierarchy process and PROMETHEE selection of power substation location, they targeted to evaluate optimal power substation location in consideration of social, technological, economic, environmental agents and site characteristics, so the decision becomes more realistic and effectual. For more details about multiple criteria decision-making 
techniques in transportation systems we refer to (Mardani et al., 2016).

We aim at designing a new decision-making model that benefits from the advantages of the above-mentioned techniques for solving the complex decision making problem of the public transportation systems. We believe that, this is a significant contribution of the proposed approach based on customer satisfaction by using survey study, statistical analysis and MCDM methods for a clear and reliable decision making judgements. Furthermore, the proposed model allows for if-what scenarios by changing the weights of criteria and observing their effects on alternatives' ranking. Also, the model can be applied to detect conflicts between criteria, and to observe the quality of the alternatives according to the passengers.

In this paper, Delphi-GAHP-PROMETHEE integrated approach is introduced for evaluating and ranking public transport systems in Tehran and the implementation process is explained with a real world case. In the application, the important criteria, which have the greatest effect on the evaluation process, are determined via a Delphi method. We use AHP method to determine the weights of criteria, and use PROMETHEE method for the final ranking and sensitivity analysis. The future investments can be made to this type mostly, and/or to the less preferred types to improve the transportation conditions.

\section{The proposed methodology}

Firstly, using Delphi method, the prime criteria as well as the structure of the decision-making problem will be determined. Then, by applying, GAHP the weights of the criteria will also be indicated, and PROMETHEE will be adopted for aggregation of the criteria, ranking of the alternatives and sensitivity analysis. This section further presents the methodological background of the research. The research methodology introduces Delphi, GAHP, PROMETHEE and the integrated Delphi-GAHP-PROMETHEE approach.

\subsection{Delphi method}

Numerous studies on public transportation systems have developed a wide variety of models based on the experts' viewpoints (Behrens and Pels, 2012; Bilişik et al., 2013; Cafiso et al., 2013). Delphi method analyzes the views of anonymous experts and connect them in written, discussion and feedback formats on a specific topic. It targets advance group decision making by looking for different views without face-to-face interaction. It is, generally, detailed as "a method of systematic solicitation and collection of judgments on a particular topic through a set of cautiously designed sequential forms, spread with summarized information and feedback of opinions derived from earlier responses" (Delbecq et al., 1975; Osborne et al., 2003). Although Delphi method enables a chance to completely add diverse experts' opinions, but it is timewasting, costly, and the state of uncertainty and vagueness still exist in experts' responses (Chang et al., 2000). Murry and Hammons (1995) recommended that Delphi method summarizes experts' opinions on a range from 10 to 30.

\subsection{GAHP method}

AHP is an influential method in decision making, which was firstly developed by Saaty (1980). It has been widely used in solving many difficult decision-making problems and the basic idea of this method is to decompose a complex MCDM problem into a system of hierarchies.

AHP is based on three principles: a) structure of the model; b) Comparative judgment of the alternatives and the criteria; and c) synthesis of the priorities. In the first step, a complex decision problem is structured as a hierarchy. The second step compares the alternatives and the criteria. In AHP, multiple pairwise comparisons are based on a regular comparison scale of 9 levels (Table 1).

Table. 1.

Nine-point intensity of importance scale and its description.

\begin{tabular}{lc}
\hline Definition & Intensity of importance \\
\hline Equally important & 1 \\
Moderately more important & 3 \\
Strongly more important & 5 \\
Very strongly more important & 7 \\
Extremely more important & 9 \\
\hline
\end{tabular}


Let $C=\{C j \mid j=1,2, \ldots, n\}$ be the set of criteria. The result of the pairwise comparison on $n$ criteria can be summarized in an $(n \times n)$ evaluation matrix A, in which every element $a_{i j}(i, j=1,2, \ldots, n)$ is the quotient of weights of the criteria, as shown in Eq. 1:

$$
\begin{gathered}
A=\left[\begin{array}{cccc}
a_{11} & a_{12} & \cdots & a_{21} \\
a_{21} & a_{22} & \cdots & a_{2 n} \\
\vdots & \vdots & \ddots & \vdots \\
a_{n 1} & a_{n 2} & \cdots & a_{n n}
\end{array}\right], \\
\mathrm{a}_{11}=1, \mathrm{a}_{\mathrm{ji}}=1 / \mathrm{a}_{\mathrm{ij}}, \mathrm{a}_{\mathrm{ij}} \neq 0
\end{gathered}
$$

At the last step, the mathematical process begins to normalize and find the corresponding weights for each matrix. The corresponding weights are provided by the right Eigenvector (w) related to the largest Eigenvalue $\left(\lambda_{\max }\right)$, as $A w=\lambda_{\max } w$. If the pairwise comparisons are completely reliable, the matrix $\mathrm{A}$ has rank 1 and $\lambda_{\max }=$ $n$. In this case, the weights can be attained by normalizing any of the rows or columns of A.

The AHP method ensures that the calculation consistency is monitored permanently in the alternative pairwise comparison procedure. The consistency is defined by the relation between the entries of A: $a_{\mathrm{ij}}$ * $a_{\mathrm{ik}}=a_{\mathrm{ik}}$. The consistency index (CI) is obtained as below:

$$
C I=\left(\lambda_{\max }-n\right) /(n-1)
$$

The final consistency ratio (CR) is calculated as the ratio of the CI and the random index (RI), as indicated in Eq. 3:

$$
C . R=C . I / R . I
$$

where, R.I is the random consistency index (n size matrix consistency index of randomly generated pairwise comparison, for which Table 2 is used).

If the value of CR is smaller or equal to $10 \%$, the inconsistency is suitable. If the Consistency Ratio is greater than $10 \%$, we have to study again the subjective judgment.

Table. 2.

Random Consistency Index (RI).

\begin{tabular}{ccccccccccc}
\hline $\mathrm{n}$ & 1 & 2 & 3 & 4 & 5 & 6 & 7 & 8 & 9 & 10 \\
$\mathrm{RI}$ & 0 & 0 & 0.58 & 0.9 & 1.12 & 1.24 & 1.32 & 1.41 & 1.45 & 1.49 \\
\hline
\end{tabular}

The Group Analytic Hierarchy Process (GAHP) allows a group of individuals to join in the decision-making process. In GAHP, every member fills up his/ her own comparisons, and records them in an individual pairwise comparison matrix. In the individual pairwise comparison matrices, each entry of the group pairwise comparison matrix is then determined as the geometric mean of the respective entries. The formula of geometric mean is as follows:

$y_{i j}=\left(\prod_{l=1}^{k} x_{i j l}\right)^{\frac{1}{k}}$

$i, j, k=1,2,3 \ldots n i \neq j$

3.3. PROMETHEE method

PROMETHEE (preference ranking organization method for enrichment of evaluation) was first proposed by Brans and Vincke (1985). The procedural steps involved in PROMETHEE II are described below:

Step 1: Calculate the preference function: There are mainly six types of generalized favourite functions as proposed by Brans and Vincke (Brans and Vincke, 1985).

$$
P_{j}(a, b)=P_{j}\left[d_{j}(a, b)\right]
$$


$d_{j}(a, b)=f_{j}(a)-f_{j}(b)$

Step 2: Calculate the combined preference function taking into consideration the criteria weights.

Combined preference function:

$\pi(a, b)=\sum_{j=1}^{k} w_{j} P_{j}(a, b),\left(\sum_{j=1}^{k} w_{j}=1\right.$

Where $\mathrm{W}_{\mathrm{j}}$ is the relative importance (weight) of the $\mathrm{j}_{\mathrm{th}}$ criterion.

Step 3: Determine the leaving and incoming outranking flows as follows:

leaving (or positive) flow for the $\mathrm{i}_{\mathrm{th}}$ alternative,

$\emptyset^{+}(a)=\frac{1}{n-1} \sum_{x \in A} \pi(a, x)$

Incoming (or negative) flow for $i_{\text {th }}$ alternative,

$$
\emptyset^{-}(a)=\frac{1}{n-1} \sum_{x \in A} \pi(x, a)
$$

Where $\mathrm{n}$ is the number of alternatives.

Step 4: Calculate the net outranking flow for each alternative:

$$
\emptyset(a)=\emptyset^{+}(a)-\emptyset^{-}(a)
$$

Step 5: Determine the ranking of all the considered alternatives depending on the values of $\varnothing(\mathrm{i})$. The higher value of $\varnothing$ (i), the better is the alternative. Thus, the best alternative is the one that keeping the utmost $\varnothing$ (i) value.

To study the evaluation problem, three main PROMETHEE tools can be used: PROMETHEE I partial ranking, PROMETHEE II complete ranking and the GAIA plane. Regarding the first tool, PROMETHEE I, the partial ranking is the result of the positive and negative outranking flows (see Formulas 3 and 4). In accordance to PROMETHEE I, alternative (a) is favored to alternative (b) if it has a high positive flow and a low negative flow. However, regarding the fact that PROMETHEE I permits indifference and incomparability situations, ranking of alternatives may be incomplete.

PROMETHEE II, based on the net preference flow, presents a complete ranking of the alternatives (see Formula 5). The Geometrical Analysis for Interactive Aid (GAIA) plane provides a graphical representation that demonstrates alternatives and their contributions to the criteria. Furthermore, a decision stick can be utilized to further study the sensitivity of the outcomes in function of weight changes (Brans and Mareschal, 1994).

GAIA matrix is built from a decomposition of the net outranking flows $\emptyset(x)$. The matrix data is then handled by a principal component analysis (PCA) algorithm and showed on GAIA biplot (Herva and Roca, 2013; Turcksin et al., 2011). PCA is utilized to decrease the number of dimensions during reduction the wastage of information. Shifting from a multi-criteria problem to a two-dimensional space and geometrical representation of relations between the alternatives and criteria provides a new viewpoint to the problem in which loss of some relative characteristics is unavoidable. To monitor its quality, it measures the amount of information conserved in the GAIA plane (Reliable GAIA planes have values larger than 70\% (Herva and Roca, 2013; Turcksin et al., 2011)).

The Decision Lab software (2000) saves up this method. Also sensitivity study on the results is possible in the software using GAIA plane, walking weights, etc.

\subsection{The integrated Delphi-GAHP-PROMETHHE approach}

The proposed model contains three basic stages: (1) Identification of the criteria to be used in the model, (2) GAHP computation and data collection, and (3) Ranking the alternatives using PROMTHEE and sensitivity analysis. The steps of the proposed Delphi-GAHP-PROMETHEE approach are shown in Fig. 1.

In the first stage, the transportation alternatives and the evaluation criteria are specified using Delphi method. After the construction of the hierarchy diagram, the weights of the criteria are calculated by GAHP method. The experts make evaluations using the Satty's scale to determine the values of the components of pairwise comparison matrices. The geometric mean of the values taken out the evaluations is calculated. Then, employing a five-point Lickert scale $(1=$ Very Bad ... 5 = Very Good $)$, the relative importance of the alternatives 
with respect to any criterion is estimated and the decision matrix is formed. Finally, the transportation ranks are computed by employing PROMTHEE method in the third stage.

\section{The numerical application}

The proposed models have been used to solve a real problem in the public transportation system in Tehran. In this section, first, the public transportation structure in Tehran is introduced. Then the proposed integrated method computations are given by considering the criteria provided via Delphi method. Finally, the sensitivity analysis is performed based on the main parameters.

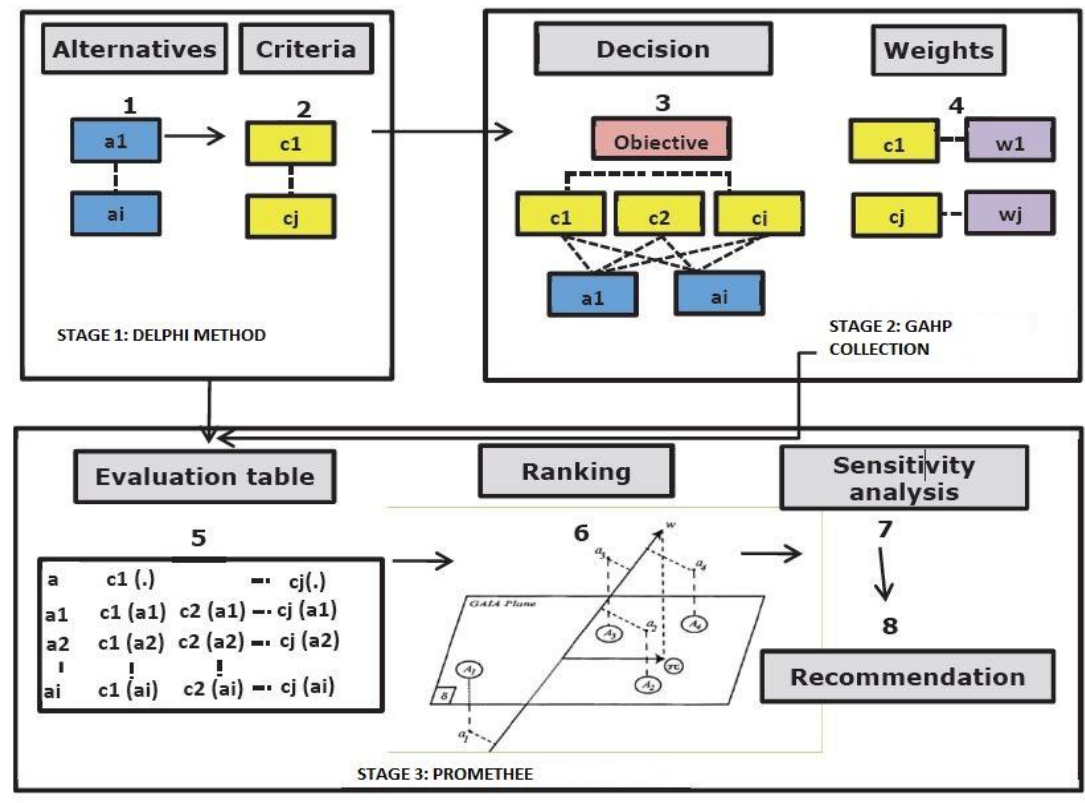

Fig. 1. The steps of the proposed Delphi-GAHP-PROMETHEE methodology.

\subsection{The public transportation structure in Tehran}

Tehran, the capital of Iran, is the largest, most congested, and the most significant city of Iran from the view point of economy, culture and history.

Nowadays, Tehran is considered one of the regions' megacities by having 8.5 million inhabitants approximately (Gohari et al., 2015). The daily arrival of people, mainly passengers, brings the 'daylight' residents of Tehran up to more than 15 million (Allen, 2011), Thus producing a worsening traffic congestion that has become more than a nuisance and turned into a major challenge for the Municipality. As a result, and in order to improve the quality of service, accessibility, and efficiency of the public transport services, Tehran City authorities has taken important steps to attract the private sector partnership into operating the public transport services.

In Fig. 2, the percentage of daily trips of transportation types in Tehran (public and private) in 2015 is shown. 


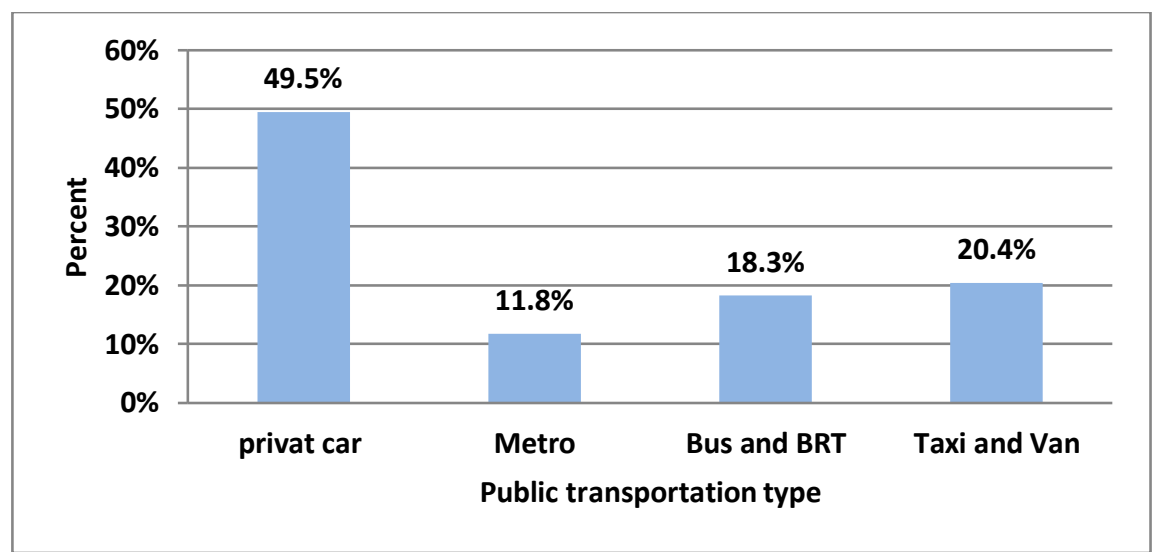

Fig. 2. The distribution of daily trips of public transportation types in Tehran (2015)

The number of passengers according to transportation types is also given in Table 3. Here, the amounts of daily trips are given based on different transportation modes. A passenger may use different transportation types in the same day, separately.

\subsection{Survey}

There are many formulas for calculating the necessary sample size based on whether the data collected is to be of a categorical or numerical nature (e.g. to estimate a proportion or a mean). In this research, we used Krejcie and Morgan (1970) Table to determine the sample size. the size of the population is more than 3,000,000, and since we aim to sample a sufficient number to produce a $95 \%$ confidence interval, so we needed the responses from a (random) sample of 384 of all population. The Cronbach alpha became 0/81.

Table. 3.

Distribution of daily passengers according to the public transportation types (www.tehran.ir, 2015).

\begin{tabular}{lccc}
\hline Public transport type & Fleet & Passenger (Million) & Percent \\
\hline Taxi & 80,000 & 4.5 & 34.7 \\
Van & 8,100 & 0.8 & 6.2 \\
Bus & 4,600 & 2.6 & 20.1 \\
BRT & 1,200 & 2.15 & 16.6 \\
Metro (wagon) & $95(1,200)$ & 2.9 & 22.4 \\
Total & 93,995 & 12.95 & 100 \\
\hline
\end{tabular}

Table. 4 demonstrates the demographic information of the participants including gender, age, and other characteristics.

Table. 4.

Demographic information of the participants.

\begin{tabular}{llcc}
\hline Question & Option & Number observed & $\%$ \\
\hline Gender & Male & 253 & 66 \\
& Female & 131 & 34 \\
Age (years) & $15-24$ & 75 & 20 \\
& $25-34$ & 144 & 38 \\
& $44-35$ & 108 & 28 \\
Vehicle ownership & $44+$ & 56 & 14 \\
& Yes & 232 & 60 \\
Educational level & No & 152 & 40 \\
& Primary school & 35 & 9 \\
& Secondary school & 42 & 11
\end{tabular}




\begin{tabular}{llcc} 
& High school & 108 & 28 \\
College/university & 154 & 40 \\
Master/doctorate & 46 & 12 \\
Economic activity & Fee-earning & 72 & 19 \\
& Self-employed & 87 & 23 \\
Student & 145 & 38 \\
Retired & 11 & 3 \\
& Housewife & 36 & 9 \\
Unemployed & 33 & 8 \\
\hline
\end{tabular}

\subsection{Delphi method}

Initially, the research was performed by survey, which included experts. Fifteen experts from engineering, academic background with Bachelor degree and average work experience of 10 years in this field were chosen to design the decision team. Thereafter, the selected criteria introduced to the decision team (expert panel) to produce the most suitable judgment for evaluation of public transportation system.

Delphi method was used to select the criteria. In the first round of the decision making process, professionals selected nine most important construction criteria. In the second round, six most important criteria were selected. So, according to the literature research and Delphi method, the criteria of selection of transport types are: travel cost, travel time, waiting time, suitability, accessibility and safety.

\subsection{GAHP calculation}

As mentioned before, the proposed integrated approach was applied after the definition of decision hierarchy model. To specify the importance weights of the criteria, we designed a form based on pairwise comparisons to be verified by the experts. Then the verified criteria were putted in the AHP decision tree (Fig. 3).

After forming the decision hierarchy for the public transportation system problem, the weights of the criteria to be used in the evaluation process were assigned, using GAHP method. The pairwise comparison of criteria was conducted by fifteen experts (The fifteen accepted comparison matrices had CR $<0.1$ ). Table. 4 shows the pairwise comparison matrix for criteria using geometric mean for the 15 experts.

The results obtained from the computations based on the pairwise comparison matrix (provided in Table. 5) are presented in Table. 6 .

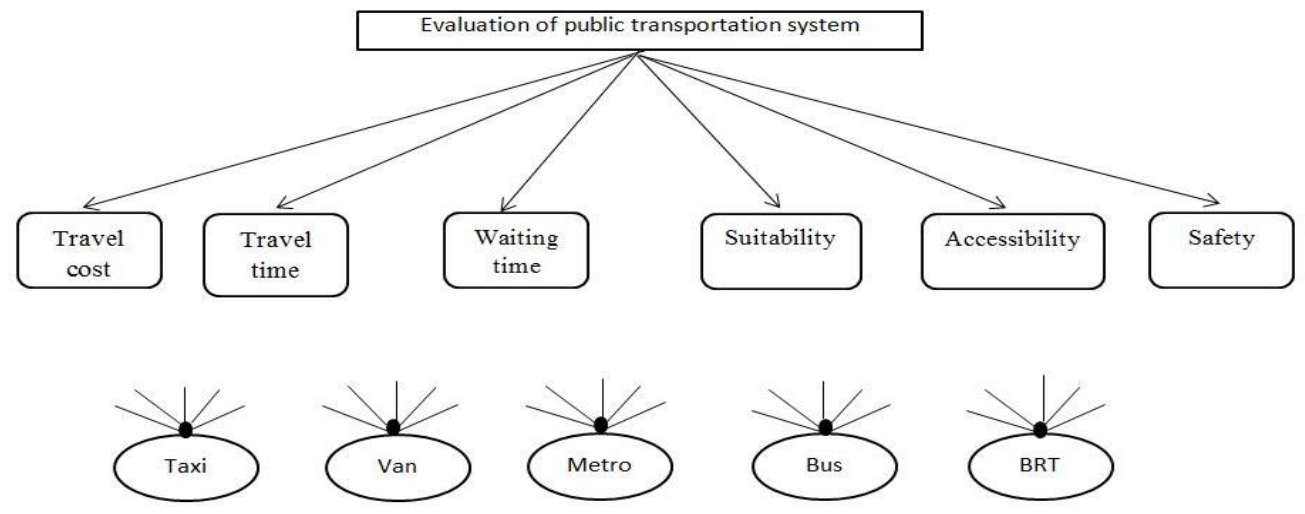

Fig. 3. Hierarchy structure of public transportation modes in Tehran.

Table. 5.

Pairwise comparison matrix for criteria obtained from GAHP.

\begin{tabular}{lcccccc}
\hline Criteria & Travel cost & Travel time & Waiting time & Accessibility & Safety & Suitability \\
\hline Travel cost & 1.000 & 0.835 & 1.074 & 1.279 & 0.437 & 0.500 \\
Travel time & 1.198 & 1.000 & 1.710 & 2.161 & 0.578 & 0.848 \\
Waiting time & 0.932 & 0.585 & 1.000 & 1.397 & 0.402 & 0.606 \\
Accessibility & 0.782 & 0.463 & 0.716 & 1.000 & 0.262 & 0.305 \\
\hline
\end{tabular}




\begin{tabular}{lllllll}
\hline Safety & 2.287 & 1.731 & 2.489 & 3.811 & 1.000 & 1.409 \\
Suitability & 1.998 & 1.180 & 1.650 & 3.279 & 0.710 & 1.000 \\
\hline
\end{tabular}

The obtained relative weights by using GAHP, steadiness index, and consistency ratio of criteria are tabulated below:

Table. 6.

Results obtained from GAHP computation.

\begin{tabular}{lcc}
\hline Criteria & Weight & Indexes \\
\hline Travel cost & 0.120 & $\lambda_{\max }=6.025$ \\
Travel time & 0.172 & $C I=0.005$ \\
Waiting time & 0.114 & $R I=1.24$ \\
Accessibility & 0.079 & \\
Suitability & 0.292 & $\boldsymbol{C R}=\mathbf{0 . 0 0 4}$ \\
Safety & 0.219 & \\
\hline
\end{tabular}

In this stage, firstly, the alternatives were assessed based on the evaluation criteria in order to compose the evaluation matrix. The result of the evaluations of these five alternatives according to the evaluation matrix are presented in Table. 7.

Table. 7.

Evaluation matrix.

\begin{tabular}{ccccccc}
\hline Criteria & Travel cost & Travel time & Waiting time & Accessibility & Safety & Suitability \\
\hline Max/Min & Min & Min & Min & Max & Max & Max \\
Weight & 0.120 & 0.172 & 0.114 & 0.079 & 0.292 & 0.219 \\
Taxi & 4.015 & 3.135 & 1.820 & 4.677 & 2.500 & 4.132 \\
Van & 3.342 & 3.433 & 2.400 & 2.267 & 2.207 & 2.240 \\
Bus & 2.873 & 3.887 & 2.846 & 2.247 & 2.400 & 2.230 \\
BRT & 2.773 & 2.833 & 2.740 & 3.148 & 3.455 & 2.213 \\
Metro & 2.545 & 2.493 & 2.586 & 3.655 & 3.867 & 2.414 \\
\hline
\end{tabular}

Before using the PROMETHEE method to rank the alternatives, for each criterion, a specific preference function (PF) with its thresholds was defined. The PROMETHEE guidelines give advice to apply a linear preference function and usual or level preference function for quantitative and qualitative assessments, respectively (Turcksin et al., 2011). The same ranking of alternatives was provided by both PROMETHEE I and II methods (Figs. 4 and 5).

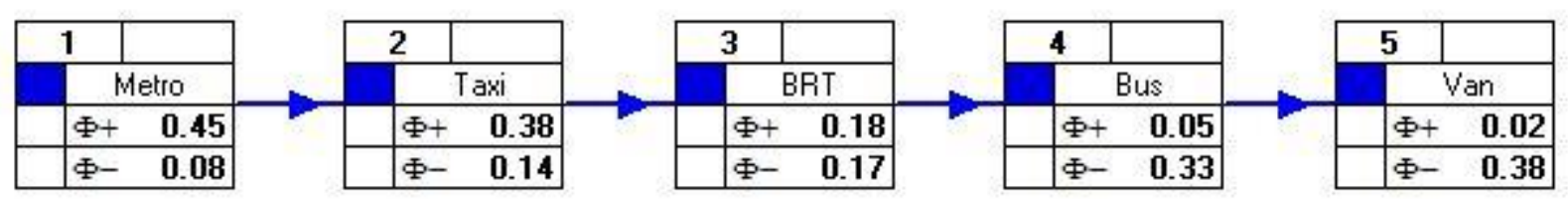

Fig. 4. Ranking of alternatives according to PROMETHEE I.

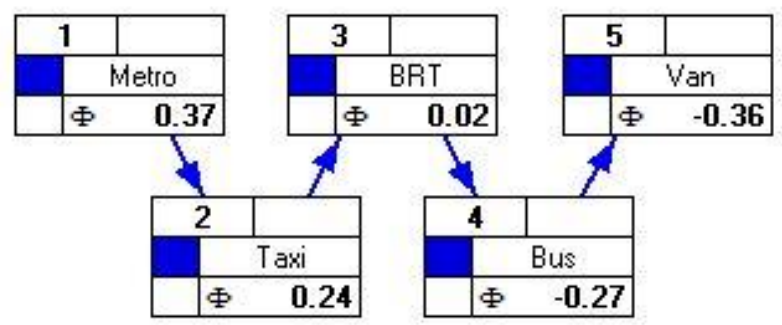


Fig. 5. Ranking of alternatives according to PROMETHEE II.

By using the evaluation matrix values (Presented in Table. 7), PROMETHEE results can be calculated. Firstly, the partial ranking was determined via PROMETHEE I (Fig. 4). PROMETHEE I used positive and negative flow values to find the partial ranking. Then the complete ranking was determined via PROMETHEE II to identify the best alternative (Fig. 5). The same ranking of alternatives was provided by both PROMETHEE I and II methods (Figs. 4 and 5). Therefore, the Van was identified as the worst alternative from the passengers' point of view, whereas the metro was evaluated as the best alternative.

\section{GAIA and sensitivity analysis \\ 5.1. GAIA}

GAIA plane can provide us with a comprehensive approach towards decision-making problem. The decision problem is visible in the GAIA plane (Fig. 6). By meaning of PCA the six-dimensional space of criteria are projected on a two-dimensional plane. Therefore, it completes the ranking conducted in the proposed method by PROMETHEE, because by this diagram, we can find helpful information about the problem. Decisionmaking problem can be indicated in GAIA, in which triangle and square are, respectively, the alternative and the criterion. Quality level or reliability of this diagram is $98.09 \%$; this means that only $1.91 \%$ of the total information gets lost by the projection. In this plane, alternatives scoring high on a particular criterion are located in the direction of the corresponding criterion axis Brans and Mareschal $(2005)$. The position of each axis is associated to its profiles on the set of criteria (i.e. actions with similar profiles will be closer to each other). Criteria terming comparable preferences have axes that are close to each other, and conflicting criteria have axes that are pointing in opposite directions Kabir and Sumi $(\underline{2014 b})$.

Figure. 6 indicates that safety has a high differentiation power. A cluster of conflicting criteria (travel cost, waiting time, and suitability express opposite preferences) are clearly represented. It is also possible to appreciate clearly the alternatives with respect to the different criteria. BRT is particularly good on travel cost, while Metro is good on both safety and travel time.

In order to differentiate the different alternatives, we will consider the length of the criterion vector is a measure of its power. On the other hand, vector pi (decision axis) shows the direction of the compromise derived from the assignment; the decision maker should appreciate the alternative situated in the same direction.

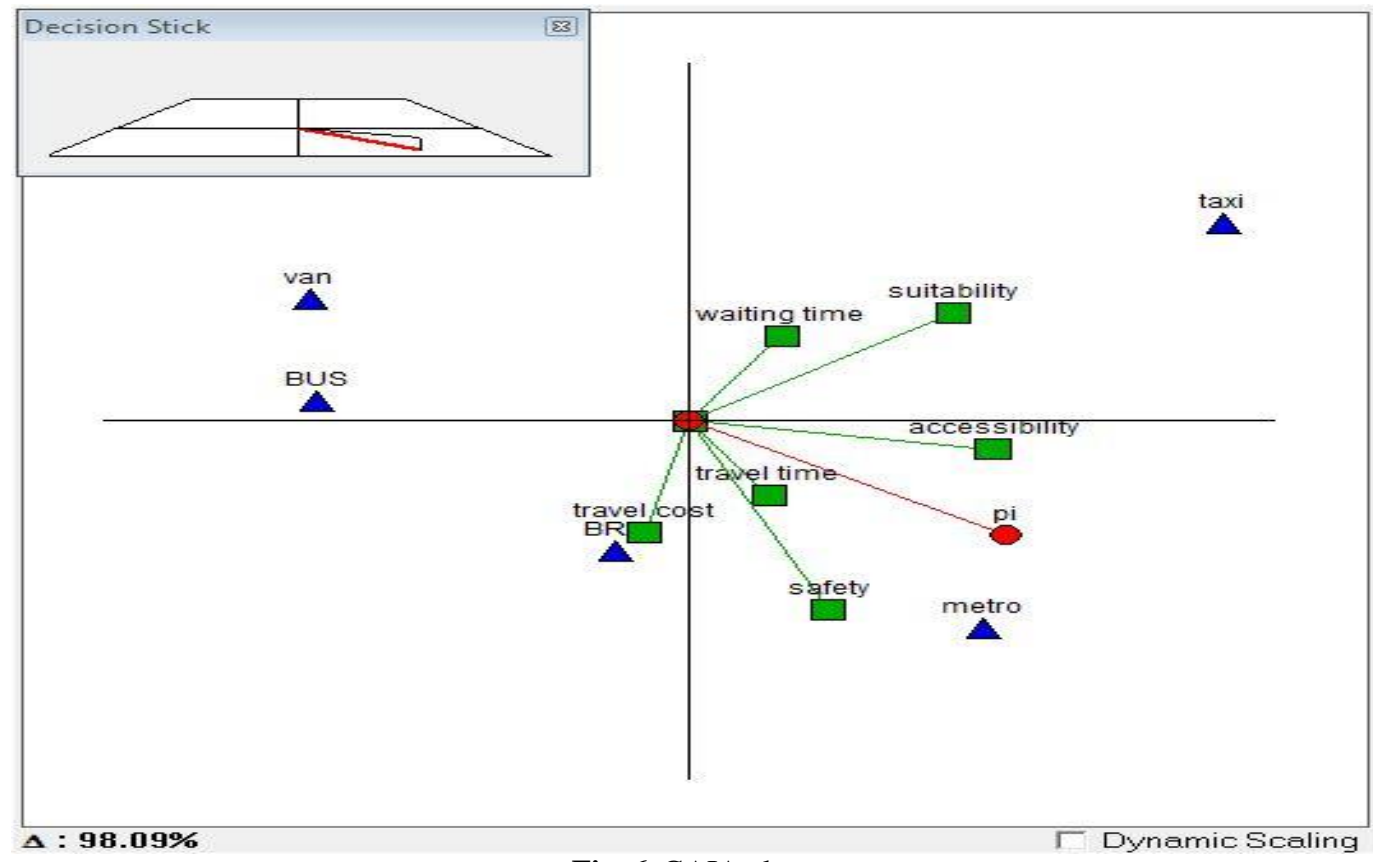

\subsection{Weight analysis}

Fig. 6. GAIA plane.

Analyzing the stability intervals (Table. 8), it was found that most of the criteria weights have a broad range. The stability interval shows within which limits, the weight of every criterion can be changed without modifying 
the PROMETHEE 2 complete ranking, as long as the relative weights of the other criteria are constant. The narrowest interval corresponded to suitability, and the widest interval corresponded to accessibility. This means that suitability is the most sensitive criterion, and accessibility is least sensitive.

Table. 8.

Weight stability intervals.

\begin{tabular}{lcc}
\hline Criteria & Current weight (\%) & Interval $(\%)$ \\
\hline Travel cost & 12.09 & {$[0.0-36.87]$} \\
Travel time & 17.26 & {$[0.0-42.12]$} \\
Waiting time & 11.44 & {$[0.0-27.29]$} \\
Accessebility & 7.97 & {$[0.0-38.53]$} \\
Safety & 29.30 & {$[17.59-55.98]$} \\
Suitability & 21.93 & {$[6.47-31.64]$} \\
\hline
\end{tabular}

Figure. 7 shows the walking weights that support the decision-maker to fulfill if-what scenarios. The weight of the travel cost criterion was calculated as $12.09 \%$ and its stability interval was between $0.0 \%$ and $36.87 \%$. Since we conducted sensitivity analysis on the upper limit, the results indicated that if the mentioned weight criterion becomes more than the upper limit, Taxi would obtain the 3rd rank and BRT would be in the second rank.

Simultaneously, if the weight of travel time criterion becomes more than the upper limit, Van would obtain the 4th rank and Bus would be the 5th. For the waiting time, if the weight becomes more than the upper limit, Taxi would be at the 1 st rank and metro at the $2^{\text {nd }}$. Regarding the accessibility, if the weight becomes more than the upper limit, Taxi will become the $1^{\text {st }}$.

The weight of safety criterion was obtained as $29.3 \%$ and its stability interval was between $17.59 \%$ and $55.98 \%$. If the weight becomes less than the lower limit, Taxi will become the $1^{\text {st }}$, but if the weight becomes more than the upper limit, the taxi would obtain the 3rd rank and BRT would obtain the second rank.

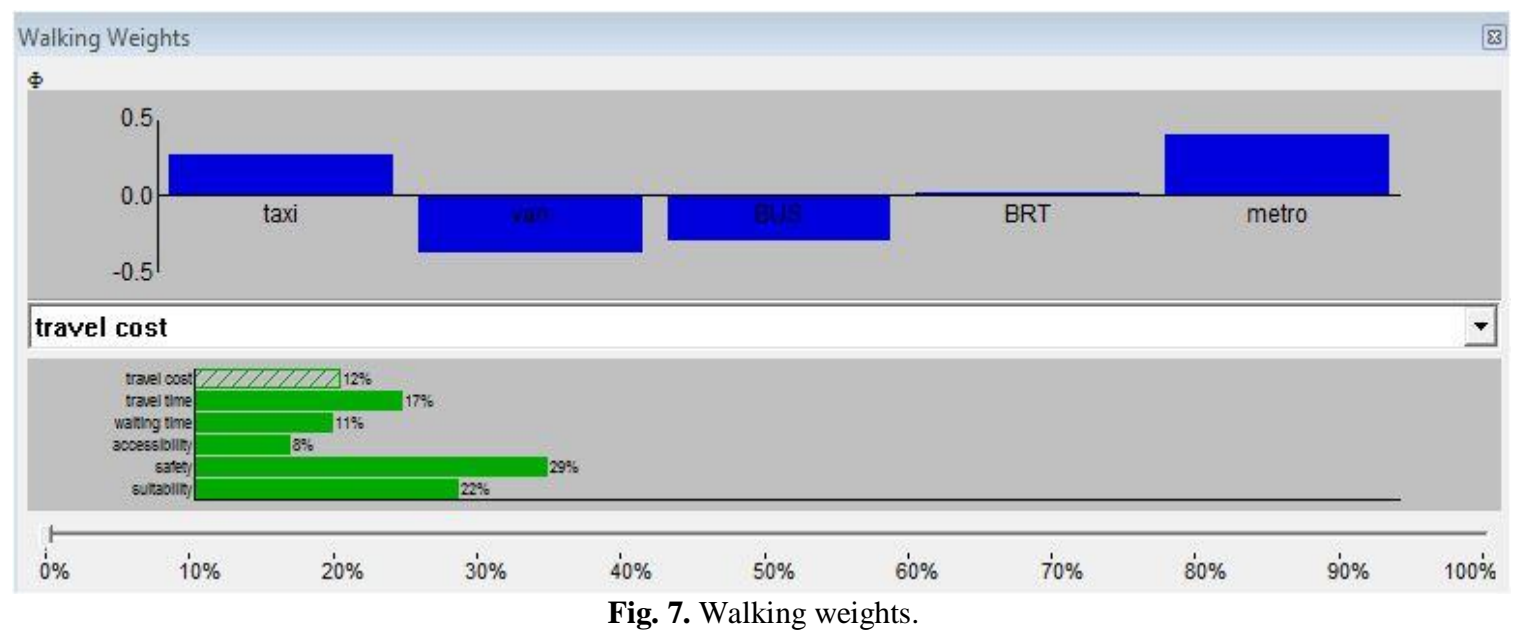

Simultaneously, if the weight of suitability becomes less than the lower limit, Taxi would obtain the 3rd rank and BRT would obtain the second rank, and if the weight becomes more than the upper limit, Taxi will be the $1^{\text {st }}$.

\subsection{Different preference functions of PROMETHEE}

In this study, seven scenarios were applied. For the first six scenarios, Usual, U-shape, V-shape, Level, Linear, and Gaussian preference functions were considered for both the qualitative and quantitative criteria, and for the last scenario, a combined Linear and Level preference function was used. The indifference thresholds were elected in order to have 5\% of the difference between the lowest and highest evaluations for each criterion, 
whereas the preference thresholds were elected in order to have $60 \%$ of the difference between the lowest and highest evaluations for each criterion. The values of the c thresholds were elected as $30 \%$ of the difference between the lowest and highest evaluations for each criterion in the Gaussian (Gervásio and da Silva, 2012).

Table. 9.

Different preference functions of PROMETHEE method.

\begin{tabular}{|c|c|c|c|c|c|c|c|c|c|c|c|c|c|c|c|}
\hline \multirow{2}{*}{\multicolumn{2}{|c|}{ alternative }} & \multicolumn{11}{|c|}{ Preference functions } & \multirow[b]{2}{*}{ Rank } & \multirow[b]{2}{*}{ Linear and level } & \multirow[b]{2}{*}{ Rank } \\
\hline & & Usual & Rank & U-shape & Rank & V-shape & Rank & Level & Rank & Linear & Rank & Gaussian & & & \\
\hline & $\varnothing$ & 0.74 & & 0.74 & & 0.33 & & 0.43 & & 0.25 & & 0.25 & & 0.37 & \\
\hline \multirow[t]{3}{*}{ Metro } & $\emptyset^{+}$ & 0.87 & 1 & 0.87 & 1 & 0.41 & 1 & 0.53 & 1 & 0.33 & 1 & 0.32 & 1 & 0.45 & 1 \\
\hline & $\emptyset^{-}$ & 0.13 & & 0.13 & & 0.08 & & 0.09 & & 0.08 & & 0.07 & & 0.08 & \\
\hline & $\varnothing$ & 0.29 & & 0.22 & & 0.19 & & 0.24 & & 0.25 & & 0.18 & & 0.24 & \\
\hline \multirow[t]{3}{*}{ Taxi } & $\emptyset^{+}$ & 0.65 & 2 & 0.57 & 2 & 0.38 & 2 & 0.42 & 2 & 0.4 & 2 & 0.34 & 2 & 0.38 & 2 \\
\hline & $\emptyset^{-}$ & 0.35 & & 0.35 & & 0.19 & & 0.18 & & 0.15 & & 0.15 & & 0.14 & \\
\hline & $\varnothing$ & 0.02 & & -0.47 & & 0.12 & & 0.01 & & 0.08 & & 0.11 & & 0.02 & \\
\hline \multirow[t]{3}{*}{ BRT } & $\emptyset^{+}$ & 0.51 & 3 & 0.13 & 4 & 0.26 & 3 & 0.22 & 3 & 0.2 & 3 & 0.21 & 3 & 0.18 & 3 \\
\hline & $\emptyset^{-}$ & 0.49 & & 0.6 & & 0.14 & & 0.22 & & 0.13 & & 0.1 & & 0.17 & \\
\hline & $\varnothing$ & -0.62 & & 0.07 & & -0.32 & & -0.32 & & -0.29 & & -0.27 & & -0.27 & \\
\hline \multirow[t]{3}{*}{ Bus } & $\emptyset^{+}$ & 0.19 & 5 & 0.45 & 3 & 0.03 & 4 & 0.07 & 4 & 0.03 & 5 & 0.02 & 4 & 0.05 & 4 \\
\hline & $\emptyset^{-}$ & 0.81 & & 0.38 & & 0.35 & & 0.39 & & 0.32 & & 0.29 & & 0.33 & \\
\hline & $\emptyset$ & -0.42 & & -0.55 & & -0.33 & & -0.36 & & -0.29 & & -0.28 & & -0.36 & \\
\hline \multirow[t]{2}{*}{ Van } & $\emptyset^{+}$ & 0.29 & 4 & 0.16 & 5 & 0.04 & 5 & 0.08 & 5 & 0.03 & 4 & 0.01 & 5 & 0.02 & 5 \\
\hline & $\emptyset^{-}$ & 0.71 & & 0.71 & & 0.36 & & 0.44 & & 0.32 & & 0.29 & & 0.38 & \\
\hline
\end{tabular}

Partial ranking based on PROMETHEE 1 and general ranking based on PROMETHEE 2 are indicated in the table. 9. The best item was Metro, but as you can see, different preference functions indicated different results.

\subsection{Scenario analysis}

To conduct sensitivity analysis, we considered different scenarios. The sensitivity analysis was based on the weight of criteria, and the selected preference function was linear and level. The first scenario was obtained through the questionnaire, but the second scenario was obtained through weighting based on Entropy method, and in the third scenario, we considered all weights of the criteria as equal. Considering the mentioned conditions, the following results were obtained (Table. 10):

Table 10

Ranks obtained with different weighting methods

\begin{tabular}{|c|c|c|c|c|c|c|c|}
\hline \multirow{2}{*}{\multicolumn{2}{|c|}{ Alternative }} & \multicolumn{6}{|c|}{ Preference Functions: Linear and Level } \\
\hline & & W GAHP & Rank & W Entropy & Rank & W Equal & Rank \\
\hline \multirow{3}{*}{ Metro } & $\varnothing$ & 0.74 & \multirow{3}{*}{1} & 0.36 & \multirow{3}{*}{2} & 0.32 & \multirow{3}{*}{1} \\
\hline & $\emptyset^{+}$ & 0.87 & & 0.47 & & 0.4 & \\
\hline & $\emptyset^{-}$ & 0.13 & & 0.11 & & 0.08 & \\
\hline \multirow{3}{*}{ Taxi } & $\varnothing$ & 0.29 & \multirow{3}{*}{2} & 0.45 & \multirow{3}{*}{1} & 0.28 & \multirow{3}{*}{2} \\
\hline & $\emptyset^{+}$ & 0.65 & & 0.55 & & 0.4 & \\
\hline & $\emptyset^{-}$ & 0.35 & & 0.1 & & 0.13 & \\
\hline \multirow{3}{*}{ BRT } & $\emptyset$ & 0.02 & \multirow{3}{*}{3} & -0.04 & \multirow{3}{*}{3} & 0 & \multirow{3}{*}{3} \\
\hline & $\emptyset^{+}$ & 0.51 & & 0.17 & & 0.16 & \\
\hline & $\emptyset^{-}$ & 0.49 & & 0.24 & & 0.16 & \\
\hline \multirow{3}{*}{ Bus } & $\varnothing$ & -0.62 & \multirow{3}{*}{5} & -0.36 & \multirow{3}{*}{4} & -0.28 & \multirow{3}{*}{4} \\
\hline & $\emptyset^{+}$ & 0.19 & & 0.04 & & 0.05 & \\
\hline & $\emptyset^{-}$ & 0.81 & & 0.4 & & 0.32 & \\
\hline \multirow{3}{*}{ Van } & $\varnothing$ & -0.42 & \multirow{3}{*}{4} & -0.42 & \multirow{3}{*}{5} & -0.32 & \multirow{3}{*}{5} \\
\hline & $\emptyset^{+}$ & 0.29 & & 0.02 & & 0.03 & \\
\hline & $\emptyset^{-}$ & 0.71 & & 0.43 & & 0.34 & \\
\hline
\end{tabular}

As shown in Table 10, The results of the first scenario (GAHP) and the third scenario are the same, but the results of the second scenario (Entropy) are different with those of the other scenarios. Of course, we used the 
Entropy method when we had no idea about the weights of the criteria. The main idea of this method is that the more scattered are the values of a certain index, the more important is that index.

6

\section{Conclusion}

Public transportation is one of the most important systems in transportation, especially in big and crowded cities, like Tehran. In such cities, public transportation is the only way to avoid traffic congestion, particularly during the rush hours.

The contributions of the paper are as follows: 1) It proposes a novel customer satisfaction evaluation approach for the urban transportation system of Tehran by integrating survey study, statistical analysis and multi criteria decision making methods. 2) In order to evaluate and enhance customer satisfaction in Tehran public transportation systems an integrated novel MCDM method based on DELPHI, GAHP and PROMETHEE was proposed. 3) The proposed method that benefits from the advantages of DELPHI, GAHP and PROMETHEE provides directions for the future investments, and the less preferred modes of public transportation can be made better to further improve customer satisfaction. (4) The suggested integrated method can be applied to complex decision making problems to deal with ambiguous, unknown and subjective data or vague information.

In this paper, a novel evaluation model for the urban transportation system of Tehran is proposed by using survey study, statistical analysis and MCDM. The results showed that the public transportation systems in Tehran in the descending order of importance are: Metro, Taxi, BRT, Bus and Van. Therefore, Tehran Municipality and policy makers should encourage and support the mentioned systems respectively.

In order to limit traffic congestion, Tehran Metro's significant development is requested due to its large fleet and passenger transport capacity. Tehran Municipality can also apply 'three-in-one' traffic policy which means only private cars with three or more passengers can use the main streets inside the capital at rush hours. This policy targets to reduce the percentage of private car, which was almost 50\%, based on Fig.2.

One long lasting solution, which is also in line with the sustainable development, is decentralization of the capital that will largely help decreasing the traffic problems. Another solution is limiting the entrance of private cars from the surrounding cities and counties into the capital traffic network through building big parking settings around the different corners of the Tehran city and development of the public transport system like Metro, BRT, etc. to the neighboring cities and counties.

The suggested decision approach can aid decision-makers to adopt and study factors and attributes easily. Moreover, the powers of this model over the existing methods can be illustrated as follows. PROMETHEE method picks into account the preference function of every criterion, specified by the decision makers. By this way, the estimation of each criterion is done on a different foundation, thus it is probable to make more enhanced decisions. PROMETHEE I supplied partial ranking so it provides the indifferent options and the incomparable options, whereas PROMETHEE II supplied a complete ranking for alternatives. The GAIA plane enables a graphical representation of the alternatives and criteria, and assist to look out for the strong and weak points of the alternatives. In addition, it helps to recognize groups of criteria having similar preferences and to better understand the conflicts that have to be solved in order to make a decision. Also, the GAIA analysis allows to determine differentiation power of the criteria, opposite criteria, independent criteria, and similar criteria.

The most influencing criteria in decision making are specified by using the PROMETHEE method when doing the sensitivity analysis of the result. These opportunities are not obtainable in the present methods such as AHP, ELECTRE, VIKOR and TOPSIS.

For some criteria having a qualitative structure or an uncertain structure, fuzzy numbers can be used to obtain the evaluation matrix. This will develop the suggested approach, thus is one of the directions in future research. Finally, as a future direction, the principles of system dynamics can be employed in our proposed model for dynamic decision-making approach.

\section{References}

Ahmad, F., Saman, M. Y. M., Mohamad, F. S., Mohamad, Z., and Awang, W. S. W. (2014). Group decision support system based on enhanced AHP for tender evaluation. International Journal of Digital Information and Wireless Communications (IJDIWC), 4(2), 248-257.

Allen, H. (2013). An Integrated Approach to Public Transport, Tehran, Islamic Republic of Iran. Global Report on Human Settlements. 
Awasthi, A., and Omrani, H. (2009). A hybrid approach based on AHP and belief theory for evaluating sustainable transportation solutions. International Journal of Global Environmental Issues, 9(3), 212-226.

Awasthi, A., Chauhan, S. S., Omrani, H., and Panahi, A. (2011). A hybrid approach based on SERVQUAL and fuzzy TOPSIS for evaluating transportation service quality. Computers and Industrial Engineering, 61(3), 637-646.

Aydin, N., Celik, E., and Gumus, A. T. (2015). A hierarchical customer satisfaction framework for evaluating rail transit systems of Istanbul. Transportation Research Part A: Policy and Practice, 77, 61-81.

Behrens, C., and Pels, E. (2012). Intermodal competition in the London-Paris passenger market: High-Speed Rail and air transport. Journal of Urban Economics, 71(3), 278-288.

Behzadian, M., Kazemzadeh, R. B., Albadvi, A., and Aghdasi, M. (2010). PROMETHEE: A comprehensive literature review on methodologies and applications. European Journal of Operational Research, 200(1), 198-215.

Bilişik, Ö. N., Erdoğan, M., Kaya, İ., and Baraçl1, H. (2013). A hybrid fuzzy methodology to evaluate customer satisfaction in a public transportation system for Istanbul. Total Quality Management and Business Excellence, 24(9-10), 1141-1159.

Brans, J.-P., and Vincke, P. (1985). Note-A Preference Ranking Organisation Method: (The PROMETHEE Method for Multiple Criteria Decision-Making). Management Science, 31(6), 647-656.

Brans, J.-P., and Mareschal, B. (1994). The PROMCALC and GAIA decision support system for multicriteria decision aid. Decision Support Systems, 12(4), 297-310.

Brans, J.-P., and Mareschal, B. (2005). PROMETHEE methods Multiple criteria decision analysis: state of the art surveys (pp. 163-186): Springer.

Buhaug, H., and Urdal, H. (2013). An urbanization bomb? Population growth and social disorder in cities. Global Environmental Change, 23(1), 1-10.

Cafiso, S., Di Graziano, A., and Pappalardo, G. (2013). Using the Delphi method to evaluate opinions of public transport managers on bus safety. Safety Science, 57, 254-263.

Celik, E., Bilisik, O. N., Erdogan, M., Gumus, A. T., and Baracli, H. (2013). An integrated novel interval type-2 fuzzy MCDM method to improve customer satisfaction in public transportation for Istanbul. Transportation Research Part E: Logistics and Transportation Review, 58, 28-51.

Celik, E., Aydin, N., and Gumus, A. T. (2014). A multiattribute customer satisfaction evaluation approach for rail transit network: A real case study for Istanbul, Turkey. Transport Policy, 36, 283-293.

Chang, S.-I., Gable, G., Smythe, E., and Timbrell, G. (2000). A Delphi examination of public sector ERP implementation issues. In Proceedings of the Twenty First International Conference on Information Systems (pp. 494-500). Association for Information Systems.

Chou, C.-C., Liu, L.-J., Huang, S.-F., Yih, J.-M., and Han, T.-C. (2011). An evaluation of airline service quality using the fuzzy weighted SERVQUAL method. Applied Soft Computing, 11(2), 2117-2128.

Del Castillo, J., and Benitez, F. G. (2012). A methodology for modeling and identifying users satisfaction issues in public transport systems based on users surveys. Procedia-Social and Behavioral Sciences, 54, 1104-1114.

Delbecq, A. L., Van de Ven, A. H., and Gustafson, D. H. (1975). Group techniques for program planning: A guide to nominal group and Delphi processes: Scott, Foresman Glenview, IL.

Dulmin, R., and Mininno, V. (2003). Supplier selection using a multi-criteria decision aid method. Journal of Purchasing and Supply Management, 9(4), 177-187.

Eboli, L., and Mazzulla, G. (2015). Relationships between rail passengers' satisfaction and service quality: a framework for identifying key service factors. Public Transport, 7(2), 185-201.

Elevli, B., and Demirci, A. (2004). Multicriteria choice of ore transport system for an underground mine: application of PROMETHEE methods. Journal-South African Institute of Mining and Metallurgy, 104, 251-256.

Emovon, I., Norman, R. A., and Murphy, A. J. (2015). Hybrid MCDM based methodology for selecting the optimum maintenance strategy for ship machinery systems. Journal of Intelligent Manufacturing, 1-13.

Fellesson, M., \& Friman, M. (2012, February). Perceived satisfaction with public transport service in nine European cities. In Journal of the Transportation Research Forum (Vol. 47, No. 3).

Friman, M., and Fellesson, M. (2009). Service supply and customer satisfaction in public transportation: The quality paradox. Journal of Public Transportation, 12(4), 4.

Gervásio, H., and da Silva, L. S. (2012). A probabilistic decision-making approach for the sustainable assessment of infrastructures. Expert Systems with Applications, 39(8), 7121-7131.

Grošelj, P., Stirn, L. Z., Ayrilmis, N., and Kuzman, M. K. (2015). Comparison of some aggregation techniques using group analytic hierarchy process. Expert Systems with Applications, 42(4), 2198-2204.

Hassan, M. N., Hawas, Y. E., and Ahmed, K. (2013). A multi-dimensional framework for evaluating the transit service performance. Transportation Research Part A: Policy and Practice, 50, 47-61.

Herva, M., and Roca, E. (2013). Ranking municipal solid waste treatment alternatives based on ecological footprint and multi-criteria analysis. Ecological Indicators, 25, 77-84.

Holmgren, J. (2013). The efficiency of public transport operations-An evaluation using stochastic frontier analysis. Research in Transportation Economics, 39(1), 50-57. 
Kabir, G., \& Sumi, R. S. (2014). Power substation location selection using fuzzy analytic hierarchy process and PROMETHEE: a case study from Bangladesh. Energy, 72, 717-730.

Kabir, G., and Sumi, R. S. (2014). Integrating fuzzy analytic hierarchy process with PROMETHEE method for total quality management consultant selection. Production and Manufacturing Research, 2(1), 380-399.

Kimiya Gohari, B., Ali Sheidaei, B., Candidate, S. R. M. P., Forough Pazhuheian, B., and Mansouri, A. (2015). Equity Chasm in Megacities: Five Leading Causes of Death in Tehran. Archives of Iranian medicine, 18(10), 622.

Krejcie, R. V., \& Morgan, D. W. (1970). Determining sample size for research activities. Educational and Psychological Measurement, 30(3), 607-610.

Lai, W.-T., and Chen, C.-F. (2011). Behavioral intentions of public transit passengers-The roles of service quality, perceived value, satisfaction and involvement. Transport Policy, 18(2), 318-325.

Lodovici, L. S., and Torchio, N. (2015). Social inclusion in EU public transport.

Mardani, A., Zavadskas, E. K., Khalifah, Z., Jusoh, A., \& Nor, K. M. (2016). Multiple criteria decision-making techniques in transportation systems: a systematic review of the state of the art literature. Transport, 31(3), 359-385.

Meier, H. (2013). Product-service Integration for Sustainable Solutions: Proceedings of the 5th CIRP International Conference on Industrial Product-Service Systems, Bochum, Germany, March 14th-15th, 2013: Springer Science and Business Media.

Mousavi, S. M., Tavakkoli-Moghaddam, R., Heydar, M., \& Ebrahimnejad, S. (2013). Multi-criteria decision making for plant location selection: an integrated Delphi-AHP-PROMETHEE methodology. Arabian Journal for Science and Engineering, 38(5), 1255-1268.

Mouwen, A., and Rietveld, P. (2013). Does competitive tendering improve customer satisfaction with public transport? A case study for the Netherlands. Transportation Research Part A: Policy and Practice, 51, 29-45.

Mouwen, A. (2015). Drivers of customer satisfaction with public transport services. Transportation Research Part A: Policy and Practice, 78, 1-20.

Murry Jr, J. W., \& Hammons, J. O. (1995). Delphi: A versatile methodology for conducting qualitative research. The Review of Higher Education, 18(4), 423-436.

Osborne, J., Collins, S., Ratcliffe, M., Millar, R., and Duschl, R. (2003). What" ideas-about-science" should be taught in school science? A Delphi study of the expert community. Journal of Research in Science Teaching, 40(7), 692720.

Pérez, J. C., Carrillo, M. H., and Montoya-Torres, J. R. (2015). Multi-criteria approaches for urban passenger transport systems: A literature review. Annals of Operations Research, 226(1), 69-87.

Ramos, D., Arezes, P., and Afonso, P. (2016). Application of the Delphi Method for the inclusion of externalities in occupational safety and health analysis. Dyna, 83(196), 14.

Saaty, T. L. (2000). Fundamentals of decision making and priority theory with the analytic hierarchy process (Vol. 6): Rws Publications.

Shiftan, Y., Barlach, Y., and Shefer, D. (2015). Measuring passenger loyalty to public transport modes. Journal of Public Transportation, 18(1), 7.

Silva, V. B., and Schramm, F. (2015). A Multi-criteria Decision Support System for Supplier Selection Decision Models in Engineering and Management (pp. 129-141): Springer.

Stelzer, A., Englert, F., Hörold, S., and Mayans, C. (2016). Improving service quality in public transportation systems using automated customer feedback. Transportation Research Part E: Logistics and Transportation Review, 89, 259-271.

Tsamboulas, D., and Mikroudis, G. (2000). EFECT-evaluation framework of environmental impacts and costs of transport initiatives. Transportation Research Part D: Transport and Environment, 5(4), 283-303.

Turcksin, L., Bernardini, A., and Macharis, C. (2011). A combined AHP-PROMETHEE approach for selecting the most appropriate policy scenario to stimulate a clean vehicle fleet. Procedia-Social and Behavioral Sciences, 20, $954-$ 965.

Tyrinopoulos, Y., and Antoniou, C. (2008). Public transit user satisfaction: Variability and policy implications. Transport Policy, 15(4), 260-272.

Tzeng, G.-H., Lin, C.-W., and Opricovic, S. (2005). Multi-criteria analysis of alternative-fuel buses for public transportation. Energy Policy, 33(11), 1373-1383.

van Lierop, D., \& El-Geneidy, A. (2016). Enjoying loyalty: The relationship between service quality, customer satisfaction, and behavioral intentions in public transit. Research in Transportation Economics, 59, 50-59.

Wang, J.-q., Han, Z.-q., and Zhang, H.-y. (2014). Multi-criteria group decision-making method based on intuitionistic interval fuzzy information. Group Decision and Negotiation, 23(4), 715-733.

Yedla, S., and Shrestha, R. M. (2003). Multi-criteria approach for the selection of alternative options for environmentally sustainable transport system in Delhi. Transportation Research Part A: Policy and Practice, 37(8), 717-729.

Yu, L., and Lai, K. K. (2011). A distance-based group decision-making methodology for multi-person multi-criteria emergency decision support. Decision Support Systems, 51(2), 307-315. 